International Journal of Biology, Pharmacy and Allied Seiences (IJBPAS) 'A Bridge Betuen Caboratory and Qnendo'

WWW.ijbpas.com

\title{
IMPORTANCE OF PALEO DIET - A REVIEW
}

\section{S.PRAVEEN KUMAR ${ }^{1}$, JOTHI PRIYA ${ }^{2 *}$ AND VINAY SIVASAMY ${ }^{3}$}

1: Research associate, Saveetha Dental College and Hospitals, Saveetha Institute of Medical and Technical Science, Saveetha University, Chennai, TamilNadu, India, 600077

2: Assistant Professor, Department of Physiology, Saveetha Dental College and Hospitals, Saveetha Institute of Medical and Technical Science, Saveetha University, Chennai, TamilNadu, India, 600077 3: Senior Lecturer, Department of Prosthodontics, Saveetha Dental College and Hospitals, Saveetha Institute of Medical and Technical Science, Saveetha University, Chennai, TamilNadu, India, 600077

*Corresponding Author: E Mail: Dr. Jothi Priya: jothipriva.sdc@saveetha.com

Received 19 ${ }^{\text {th }}$ March 2021; Revised 20 ${ }^{\text {th }}$ April. 2021; Accepted $19^{\text {th }}$ May 2021; Available online $1^{\text {st }}$ Aug. 2021 https://doi.org/10.31032/IJBPAS/2021/10.8.1026

\begin{abstract}
The aim of the study is to estimate the effect of paleo diet and to determine current knowledge on the same and to create awareness on Palaeolithic diet. The Palaeolithic diet is called the paleo diet, caveman diet or Stone Age diet is mainly based on foods presumed to be available to Palaeolithic humans. Like other famous diets, the paleo diet is promoted as a way to improve health. Limited data exist on metabolic effects on humans eating the die, though the available data suggest following this diet may lead to improvements in terms of body composition and metabolic effects as compared to the typical western diet. The diet is a fast growing trend and hence changes and awareness have to be made. Even though the diet is very diverse, most people don't follow correct diet patterns and tend to eat the wrong food. Therefore, it is imperative that awareness is generated about the diet. Articles are collected and then a detailed study was made, the results have been given accordingly. We have come to know the preference of diet among the people is paleo. Palaeolithic diet is more preferred because of its benefits.
\end{abstract}

Keywords: Paleo diet; Palaeolithic period; proteins; carbohydrates; exercise 


\section{INTRODUCTION}

The general medical community in "paleolithic nutrition "was introduced by anthropologists Eaton and Konner in 1985. It refers to the period of genus homo, beginning more than 2 million years ago and continuing until about 10000 years ago when humans began to pet domestic animals and cultivate plants [1]. Our ancestors, including Homo sapiens, lived as hunters, eating wild animal source foods and uncultivated plant source foods. Beginning of agriculture and animal domestication leave little time for evolutionary forces to redesign the core metabolic and physiological processes in a major way in response to the major dietary changes [2, 3]. The evolution and development of modern diet increases the diseases because it is not natural and it reduces the immunity $[4,5]$. As the lifestyle changes the diet also changes and leads to an increase in cardiovascular diseases [6]. It is one of the 35 most popular diets of the world and it is known as the best diet [8]. The contemporary American diet differs from paleolithic type diets as a consequence of the industrial revolution and more recently the fast food revolution [5]. High intake of vegetables, fruits and meat; moderate intake of nuts, berries and honey ; low intake of grains and no intake of milk or dairy products, legumes, salt, alcohol or refined carbohydrates are the key features of the paleo diet [2]. It includes eating whole, unprocessed foods like grass fed meat; free range poultry; wild fish; vegetables; fruits; berries; nuts and seeds. It avoids grains, legumes, refined sugars, dairy products and artificial beverages. The diet is mainly composed of unsaturated fat. Reduced intake of saturated fat reduces the risk of cardiovascular diseases. When compared with the Mediterranean like diet, paleo diet improves glucose tolerance [7].

People hugely follow a paleo diet to lose weight. By doing nothing else but switching over to a paleo way of eating many will notice that the weight just starts decreasing . Experiments shows that proteins have special property of insulinotropic and glucose lowering properties by which it prevents the type 2 diabetes . Since paleo is basically a protein based diet it prevents type 2 diabetes [8]. Intake of protein also increases bone health. It provides detoxifying effects by stopping the intake of a phytonutrients fibre vegetables and getting more antioxidants from fruits which purge our body from the buildup of waste and accumulation. The low salt intake lowers the risk of hypertension .It helps us to get good sleep by cutting out the 
chemicals in typical food sources that our body will naturally get tired at night [2]. So the main aim of this study is to create awareness among the population about paleo diet.

\section{A. Functions:}

A ketogenic diet primarily consists of highfats, moderate-proteins, and very-lowcarbohydrates. The dietary macronutrients are divided into approximately $55 \%$ to $60 \%$ fat, $30 \%$ to $35 \%$ protein and $5 \%$ to $10 \%$ carbohydrates. Specifically, in a $2000 \mathrm{kcal}$ per day diet, carbohydrates amount up to 20 to 50 g per day.

\section{B. Clinical Significance:}

The popular belief that high-fat diets cause obesity and several other diseases such as coronary heart disease, diabetes, and cancer has not been observed in recent epidemiological studies. Studies also found that these people had decreased blood sugar levels as well as decreased systolic blood pressure. In short, researchers found that a paleo diet may help improve people's type 2 diabetes symptoms and, as a result, improve overall heart health [9]. Studies carried out in animals that were fed high-fat diets did not show a specific causal relationship between dietary fat and obesity.Some data have shown that a paleo diet has a significant and persistent effect on lowering liver fat compared to a low-fat diet, simply because a low-fat diet isn't palatable to a lot of people [10]. On the contrary, very-low-carbohydrate and high-fat diets such as the ketogenic diet have shown to be beneficial to weight loss. Paleo diet also eliminates the main culprits behind that inflammation - especially blood-sugar surges triggered by excess sugar and grain. One preliminary study even found that a Paleo diet relieves signs of thyroidsuppressing inflammation by up to 82 percent $[11,12]$.

The prevalence of obesity has been rapidly rising over the few decades globally and in India. Obesity also predisposes individuals to type 2 diabetes, hypertension and cardiovascular disease apart from osteoarthritis, sleep apnoea and even some forms of cancer. Obese individuals are also prone to psychological issues such as low self-esteem and depression. Medical intervention to manage obesity is very few, and most of them only work with a robust lifestyle intervention programme. This leads to frustration among individuals with obesity, leading them to resort to extreme dietary interventions to obtain quick weight loss. One such extreme dietary intervention which has gained popularity in recent years is the ketogenic diet. The Paleo diet is antiinflammatory, and most people experience 
reduction of pain associated with inflammation. Improvements in those with respiratory problems such as asthma [13-16]. In this study, researchers studied 21 overweight volunteers for 8 weeks. They fed them either a low-calorie diet or a keto diet and also had them start strength training. Both groups gained about the same amount of strength, while losing about the same amount of weight. They concluded that a keto diet isn't some amazing magic for strength training, but it also doesn't hurt at all, at least during weight loss. This study reported similar results during 8 weeks of resistance training [17-19].

\section{What are ketogenic diets?}

Ketogenic diets are characterized by a marked reduction in carbohydrates (usually to $<50 \mathrm{~g}$ /day) and a relative increase in the proportions of protein and fat - usually extremely high percentages of fat because it is difficult to increase proteins beyond a point.

\section{Types of ketogenic diets:}

* Standard ketogenic diet (SKD): This is a very low-carbohydrate diet with moderate-protein and high-fat diet. It typically contains 70 percent fat, 20 percent protein and only 10 percent carbohydrates.

\section{* Cyclical ketogenic diet (CKD): This} diet involves periods of highercarbohydrates in between the ketogenic diet cycles, for example, five ketogenic days followed by two high-carbohydrate days as a cycle.

- Targeted ketogenic diet (TKD): This diet permits adding additional carbohydrates around the periods of the intensive physical workout.

* High-protein ketogenic diet (HPKD): This diet includes more protein and the ratio around 60 percent fat, 35 percent protein and five percent carbohydrates but as can be seen, it is still a very high fat diet.

The SKD and HPKD have been used extensively. The cyclical and targeted ketogenic diets are recent additions and mostly used by bodybuilders or athletes. The SKD is the most researched and recommended, and the rest of this article will deal with SKD.

\section{E. Benefits and adverse effects of ketogenic diets:}

The ketogenic diet was originally developed in 1924 to treat epilepsy [20] but other, more recently discovered benefits include weight loss and reversal/control of type 2 diabetes [8]. Use of ketogenic diets in weight management has gained tremendous 
popularity, but it has also generated several controversies. Some researchers suggest that there are no metabolic advantages with low carbohydrate diets and that weight loss results simply from reduced caloric intake, probably due to the increased satiety effect of protein [21]. However, the majority of ad libitum studies individuals who follow a lowcarbohydrate diet lose more weight during the first 3-6 months compared with those who follow more balanced diets [22]. Research on the effects to sleep on highprotein and high-carbohydrate diets is mixed. Some studies have shown people with sleep disorders such as insomnia and sleep apnea tend to consume less carbohydrates than people without these sleep disorders. Other research shows reductions to slow-wave sleep in people who consume high-carb diets, compared to low-carb [23].

Besides a positive effect on weight loss, studies have shown that low-carbohydrate ketogenic diets also reduce serum triglycerides dramatically. Elevated serum triglycerides are common among Asian Indians, and this is one of the features of the so-called Asian Indian Phenotype [24]. The keto diet, which emphasizes eating lots of fats and restricting carbohydrates, can lead to NAFLD, according to research [25-26]. Reduction in total cholesterol and increase in high-density lipoprotein cholesterol have also been reported. A key enzyme in cholesterol biosynthesis is 3-hydroxy-3-methylglutarylCoA reductase, which is activated by insulin. This means that an increase in blood glucose and consequently of insulin levels will lead to increased endogenous cholesterol synthesis. But the paleo diet emphasizes eating more animal protein. Doctors at Harvard found that replacing carbs with animal protein was linked to a $32 \%$ higher risk of infertility in women $[\mathbf{7}, \mathbf{8}, \mathbf{1 1}, \mathbf{2 6}]$. A reduction in dietary carbohydrate will thus have the opposite effect and this, coupled with the additional inhibition by dietary cholesterol and fats on endogenous synthesis, is likely to be the mechanism by which physiological ketosis can improve lipid profiles. Some studies suggest that paleo really does offer benefits, like weight loss and more energy, while others show anecdotal evidence that eliminating inflammatory foods in the standard American diet — such as soda, chips, and cookies — as well as grains, legumes, and most dairy, can help people manage diseases like inflammatory bowel disease (IBD), psoriasis, and multiple sclerosis (MS) [27-29].

\section{DISCUSSION}

Indian diets are very high in carbohydrates. The STARCH study has shown that Indians 
with or without diabetes consume at least 65 percent calories from carbohydrates. The Chennai Urban Rural Epidemiology Study (CURES) has also shown that carbohydrate constitutes the major source of calories in south India.By contrast, higher fat intake was associated with lower risk of total mortality, non-cardiovascular disease mortality and stroke. In contrast, in a recent study on dietary carbohydrate and mortality, Seidelmann et al showed that there existed a U-shaped relationship between carbohydrate intake and mortality. Both extremely high (60\% and above) and low carbohydrate diets ( $<30 \%$ carbs) were shown to have higher mortality rates. The risk of dying was lowest when the carbohydrate intake was between 50 and 55 per cent. The biggest problem with extreme diets like keto diets is their sustainability. In our experience, people are initially thrilled with the weight loss and the excellent diabetes control they get, after using keto diets. Slowly, however, they get bored with the diet. Furthermore, many feel weak and frustrated and start increasing the carbohydrate intake, and soon they are back to their original weight and diabetes control.

\section{CONCLUSION}

The dictum, 'Moderation is the key' should be used, while following any long-term diet plan. While a low-carbohydrate ketogenic diet does, admittedly, show dramatic improvements in the short term, these can increase morbidity and mortality in the long run and are rarely sustainable. Such a diet may not immediately give dramatic results as far as weight reduction is concerned. However, it will be sustainable in the long term and will be less risky and certainly more healthy and also help prevent noncommunicable diseases such as diabetes, cardiovascular disease and certain cancers. However, this review is done in order to know about the importance of paleo diet in our day today life for a healthy lifestyle.

\section{ACKNOWLEDGEMENTS:}

The authors are thankful to Saveetha dental College for providing a platform to express our knowledge.

\section{CONFLICT OF INTEREST:}

The authors declare no conflict of interest.

\section{REFERENCES}

[1] Sebastian A, Frassetto LA, Sellmeyer DE, Merriam RL, Morris Jr RC (2002). Estimation of the net acid load of the diet of ancestral preagricultural Homo sapiens and their hominid ancestors. Am J Clin Nutr 76, 1308-1316.

[2] Osterdahl M, Kocturk T, Koochek A, Wandell PE(2007). Effects of a shortterm intervention with a paleolithic 
diet in healthy volunteers. Eur J Clin Nutr62, 682-685.

[3] Eaton SB, Cordain L (1997). Evolutionary aspects of diet: old genes, new fuels. Nutritional changes since agriculture. World Rev Nutr Diet 81, 26-37.

[4] Cordain L, Eaton SB, Sebastian A, Mann N, Lindeberg S, Watkins BA. (2005). Origins and evolution of the Western diet: health implications for the 21st century. Am J Clin Nutr 81, 341-354.

[5] Myles IA. Fast food fever: reviewing the impacts of the Western diet on immunity. Nutr J 2014; 13: 61 . CrossRefMedlineGoogle Scholar.

[6] M. Ashfaq Ahmed*, DR. Geetha, Int. J. Pharm. sci. Rev. Res., 44(1), May June 2017; Article No. 20, Pages: 7375.

[7] O'Keefe Jr JH, Cordain L (2004). Cardiovascular disease resulting from a diet and lifestyle at odds with our Paleolithic genome: how to become a 21st-century hunter-gatherer. Mayo Clin Proc 79, 101.

[8] U.S. News evaluated 35 of the most popular diets and identified the best. US News and World Report 2015 Jan 6 [cited 2015 Apr 28]. Available from: http:/health.usnews.com/best$\operatorname{diet} /$ paleo-diet/reviews.

[9] Lindeberg S, Jönsson T, Granfeldt Y, Borgstrand E, Soffman J, Sjöström K, Ahrén B. A Palaeolithic diet improves glucose tolerance more than a Mediterranean-like diet in individuals with ischaemic heart disease. Diabetologia 2007;50:1795807. CrossRefMedlineGoogle

Scholar.

[10] Chen M, Sun Q, Giovannucci E, Mozaffarian D, Manson JE, Willett WC, Hu FB. Dairy consumption and risk of type 2 diabetes: 3 cohorts of US adults and an updated metaanalysis. BMC Med 2014;12:215. CrossRefMedlineGoogle Scholar.

[11] Wheless JW. History of the ketogenic diet. Epilepsia. 2008;49(Suppl 8):3-5.

[12] Westerterp-Plantenga MS, Nieuwenhuizen A, Tomé D, Soenen S, Westerterp KR. Dietary protein, weight loss, and weight maintenance. Annu Rev Nutr. 2009;29:21-41.

[13] Paoli A, Rubini A, Volek JS, Grimaldi KA. Beyond weight loss: A review of the therapeutic uses of very-low-carbohydrate (ketogenic) 
diets. Eur J Clin Nutr. 2013;67:789-

96.

[14] Shah VN, Mohan V. Diabetes in India: What is different? Curr Opin Endocrinol Diabetes Obes. 2015;22:283-9.

[15] Samuel, A.R., Devi, G, Geographical distribution and occurrence of endemic goitre, 2015 Research Journal of Pharmacy and Technology, Vol 8(8), pp 973-978.

[16] Baheerati, M.M., Gayatri Devi, R, Obesity in relation to infertility, 2018, Research Journal of Pharmacy and Technology Vol 11 (7), pp 3183-3185.

[17] Fathima, F., Preetha, Evaluation of thyroid function test in obese patients, 2016, Asian Journal of Pharmaceutical and Clinical Research, Vol 9(special issue 1),pp : 353- 355

[18] Ilankzhai, RG Devi, Rj, I., and G. D. R.. Role of environmental factors on sleep patterns of different age groups: a survey- based study. Asian Journal of Pharmaceutical and Clinical Research. 2016. Vol. 9, no. 6: pp. 124-6, doi: 10.22159/ajpcr.2016.v9i6.13832.
[19] Harsha, L., Priya, J., Shah, K.K., Reshmi, B, Systemic approach to management of neonatal jaundice and prevention of kernicterus, 2015;Research Journal of Pharmacy and Technology Vol 8(8), pp : 10871092

[20] PH Dave, Preetha S. Pathogenesis and Novel Drug for Treatment of Asthma-A Review, Research Journal of Pharmacy and technology (2016) 9 (9), 1519-522.

[21] Abigail, Jothi Priya, A., Devi, G.Evaluation of muscular endurance among dentists, Indian Journal of Public Health Research and Development, 2019, 10, 10, 258 261

[22] David, Jothi Priya, A., Devi, G,Physical fitness among the dental physician, dental undergraduates and postgraduates students, Indian Journal of Public Health Research and Development, 2019, 10, 10, 223 $-226$

[23] Shruthi, M., Preetha, S, Effect of simple tongue exercises in habitual snorers; 2018; Research Journal of Pharmacy and Technology ; vol 11( 8); pp : 3614- 3616. 
[24] Choudhari, S., Jothipriya, A.Nonalcoholic fatty liver disease, Research Journal of Pharmacy and Technology 2016, 9,10,1782 -1785.

[25] Iyer, P.K., Gayatri Devi, R., Jothi Priya, A, A survey study on causes, treatment and prevention of onychocryptosis, 10,8,807-811.

[26] Gayatri Devi, R., Sethu, G, Evaluation of adenoids by oronasal and nasal spirometry, 2018 ; Asian Journal of Pharmaceutical and Clinical Research, Vol 11(10) PP 272- 27

[27] Swathy, S., Sethu, V.G. Acupuncture and lower back pain. Research Journal of Pharmacy and Technology. 2015; 8(8): 991-993. 